The reduction of the problem of X-ray diffraction to wave-mechanics has been developed in papers by Laue and his co-workers Kohler, Moliere, Lamla, but it is given a more connected discussion in this book. Its main advantage is the uniformity of method in treating the scattering by atoms, molecules and crystals, and for the latter the foundation of the dynamical theory on the Fourier series for the electron density in the crystal.

Among the problems that have to be dealt with by the dynamical theory are the intensity of reflexion by a perfect crystal, the multiple reflexion resulting in a weakening (Aufhellung) or strengthening (Umweganregung) of the main reflexion, and the "lattice source method" of diffraction of Kossel. The latter has been reduced in a most elegant way by Laue to the established formalism of the dynamical theory by using an optical reciprocity theorem which relates the intensity received outside the crystal from a source inside it to the intensity created by an external source at the point of emission within the crystal.

Apart from the dynamical theory, the optical side of the theory of the temperature factor has been treated with great care and clarity by v. Laue. It is true that this theory remains on the level of the 'kinematical' theory of diffraction which includes only such effects as result from composing scattered wavelets derived from a single primary (incident) wave of given propagation. Instead, the treatment to be aimed at should be to study the propagation of an optical field, consisting of an indefinite number of waves of adaptable velocities, through the temperature-disturbed erystal, in the same way as it is done for the undisturbed crystal in the dynamical theory.

This combined thermal-dynamical theory has so far not been attempted. Laue's treatment is, however, superior to most previous presentations in employing a uniform method for discussing the temperature effect on the scattering by molecules and by crystals. In both systems the thermal displacements can be regarded as due to superimposed normal oscillations about the equilibrium position, and the independent co-ordinates of the system are its normal co-ordinates which perform simple harmonic oscillations of frequencies, say, $v_{j}$. As a result of these, the scattered radiation can be expressed as a sum of components of Doppler-modified frequencies $\omega \pm p v_{j}$, where $\omega$ is the X-ray frequency, and $p$ any integer. The intensities of the components are given by Bessel functions, the arguments of which are the 'roughnesses' produced in the reflecting plane by each type of lattice vibration. The main difficulty of the calculation lies in the fact that since the 'roughness' is of the order of the X-ray wave-length, the change of phase produced by the superposition of lattice vibrations is not simply the sum of the phase differences due to each vibration. The result of Laue's careful discussion is that wavelets of unmodified frequency $(p=0)$ are collected in principal and secondary maxima of the same directions as for a lattice without thermal motion; the atomic factors $f_{n}$ have to be replaced by $f_{n} D_{n}$, where $D_{n}$ is a Debye factor containing in its argument the mean square displacement of the $n$th kind of atom taken along the normal to the reflecting plane. All the background scattering is due to radiation of Doppler-modified frequencies $\omega \pm p v_{j}$ with $p \neq 0$, but the change of frequency is too small to be readily detected by experiment. In stressing the Doppler effect, Laue's theory of the thermal factor differs from the recent treatment on wave-mechanical lines given by Born and Miss Sarginson and others, but it seems unlikely that the results would be greatly affected.

As a second step, of purely dynamical, not optical, theory, the mean square displacements of the atoms, resolved along the normal to the reflecting planes, have to be calculated as functions of the temperature. Laue's book, stressing the optical part, does no more than outline this problem.

In the last third of the book, which deals with the dynamical theory, many interesting details will be found apart from the general approach which has already been described above. The theory of Renninger's 'multiple reflection' and of Kossel's 'crystal source method' are worked out; with respect to the former it seems a pity that no attention has been given to the experimental and theoretical work of Weigle and co-workers. A careful discussion is given of the transition from the dynamical to the kinematical theory in the case of small crystals. Another item is the dynamical theory for frequencies near to an absorption edge, following a paper by G. Moliere.

Anyone familiar with the subject will appreciate the sound physical and mathematical basis of v. Laue's book, and the many original and critical ideas incorporated in it. The reading is not difficult in spite of the fairly involved mathematics, and the limitation of the book to points of major optical interest excludes detail which may be necessary for the discussion of experimental data, but which would fatigue the general reader. It is to be hoped that the author may find it possible to complete a similar account of the theory of electron diffraction, a closely related subject on which he has been engaged for the last ten years simultaneously with the subject presented in this volume.

\section{KEY METALS AND THE LOCATION OF INDUSTRY*}

\author{
BY Prof. C. B. FAWCETT \\ University College, London
}

$\mathrm{F}$ ROM the beginnings of man's knowledge of metals up to about two hundred years ago, the number of known metals could be counted on his fingers. There were the 'noble', but not particularly useful, gold and silver, and such 'base' metals as copper, iron and lead, which made up for their baseness by being useful. Mercury also has long been known. Bronze and brass were known; though it is doubtful whether their composition and their relations to copper, tin, and zine and antimony were understood before the eighteenth and nineteenth centuries. The number now known is five times as great. But, except for aluminium, the newer metals are chiefly of importance for their part in the formation of many alloys with the older metals. Iron is still by far the most important base of such alloys, and the most important of all the metals.

The effects on human society of so great an addition to available natural resources are both complex and far-reaching. But here I wish to note only some effects of the use of the key metals on the location

* Paper read at the Conference on Mineral Resources and the Atlantic Charter, arranged by the Division for the Social and International Relations of Science of the British Association, on July 24. 
of industry, which is an important factor in the economic and social organization of a modern civilized community.

These key metals are used chiefly in forming, with iron, most of the many steels which are now known and used. Up to a century ago, the only important steel was carbon steel, which had been known to some extent for perhaps two thousand years. But though it was known, in the sense that it could be produced by the smelting of some forms of iron with some forms of charcoal, that knowledge was only empirical. Before the middle of the nineteenth century the making of steel on any large scale was still something of a gamble. The process could not be understoodand so controlled-until the sciences of chemistry and metallurgy had made considerable progress. Then came the systematic study of iron and steel. This led to a knowledge of the solvent powers of molten iron; and so to a study of the properties of the solidified solutions-the steels. Such investigation demanded large-scale organized research, and most of it dates only from the present century, particularly during and after the War of 1914-18. Not all the steels are of present importance. But some of them are so much so that they have caused a revolution in tool materials. There are now steels which are respectively harder, tougher, less corrodable, more resistant to softening at high temperature, etc., and so more efficient for particular purposes, than any formerly known. We have now better cutting steels than before, and others better for other purposes.

It is probably true to say that the sudden improvement in one tool material within this century is a change comparable to that from the ages of stone to the ages of bronze and of iron. Its social effects are not likely to be less than those of the first introduction of metals as tool materials.

The more important of these key metals include chromium, and cobalt, manganese, molybdenum and nickel, tungsten and vanadium-a list which is far from being exhaustive.

In relation to the location of industry, and their effects on it, it may be noted that these motals normally occur in quantities which are small in comparison to the ore bodies of the longer-known iron and copper, and they are found chiefly in rocks of Archean types; and so in areas away from the fertile lands of dense agricultural settlement and also away from the great coal deposits, which are not found in rocks older than the carboniferous. So the sources of the key metals are, for the most part, in remote and thinly populated areas. Secondly, the key metals are used in small quantities, very rarely forming as much as 10 per cent of a steel, and usually much less. So that where iron is needed in thousands or millions of tons the key metal is needed only in tens or thousands of tons. Thirdly, in its relation to industry, it is characteristic that the whole of a key metal used becomes part of the final product. The amount wasted in the process of manufacture is negligibly small.

Many of these metals are found in such a form that the metal itself is only a small proportion of the material mined. Hence there is usually a process of 'concentration' at, or very near, the mine. The location of the mine itself, and of this 'concentration', is of course determined by the place of occurrence of the ores. But once the concentrate is obtained, it is transported to existing centres of industry to be refined and then used; and it seems that the place of occurrence of the ores of the key metal has, in most cases, little or no influence on the location of the industry which uses it.

Let us consider, very briefly, some factors influencing the location of manufacturing industry, and their relation to these motals. Such factors may be grouped as primarily economic, or social, or political, though some may come under more than one of these heads.

The economic factors are chiefly those concerned with the needs for transport and power. In respect to the first, the materials to be used can be divided into $(a)$ those which are wholly or mainly used up in the processes of manufacture, and $(b)$ those which, like the key metals, form part of the finished product. The latter must, in all cases, be transported from their place of origin to the final user of the product ; and usually it makes little difference to cost where they are stopped on this journey to undergo the transformation from raw materials to finished goods. There is, however, a difference according to whether the use is widespread or concentrated. In the case of the key metals it is mostly the latter; for the alloys containing them are built into tools most of which are used in industry (or armaments) and not spread widely in small lots. So there is, in general, an attraction of these materials to the regions of heavy industry, the location of which has been previously determined by facts independent of these metals.

The other chief economic factor is the power required in the manufacture; though this, especially when it is in the form of coal, might be classed as a material which is wholly used up in the processes of manufacture. There is thus a great saving in reducing the transport of such power. This was the attraction which, in the palæotechnic period, brought heavy industries to the coalfields; and it is still important, though the more recent electrical transmission of power has lessened the pull of the coalfields.

The chief social factors in the location of an industry are related to the amount and kind of the labour it needs. In this respect the key metals are easily classed. They are almost wholly used in industries, and sections of industries, which are dependent on highly skilled labour; and the products into which they enter go to similar industries. Hence the key metals come almost exclusively to regions of highly developed--and so generally of long standing - metal industries. By aiding the development of, and the demand for, skilled work, they tend to confirm the existing location of those industries. Up to the present, except for some Government armament industries as in Japan, practically all the key metals are used in the two great zones of established manufacturing industries in eastern North America and in Britain and Europe.

The political factors are very different in their effects. Here the dominant factor is that the key metals are essential to the armaments industry and to the making of tools which produce armaments. Hence, in a world of independent sovereign States, no State can feel itself secure or really independent unless it has within its borders a considerable armaments industry. In fact, no State which is not an important industrial power can, to-day, be an important political power. Thus the political influenees on the location of industries are particularly obtrusive in relation to those in which the key metals are vital, and in recent years such political forces have been of primary importance. 
The economic and social factors which tend towards the location of the industries using the key metals near the centres of older metal-working industries are further strengthened by the recent tendency-very prominent in steel-making - to an increasing use of 'scrap metal' as a raw material, which has long been practised with the more expensive metals. A note in the Monthly Labour Review of May, 1935 (p. 1155) states that in the U.S.A. "scrap iron and steel" formed $\mathbf{9 . 9}$ per cent of all the materials used in steelmaking, and approximately half of that of the finished steel. These proportions may have increased under war conditions. They are likely to remain high, and to be applied to all metals, if we can attain a sanely conservative use of our metal resources. In that case we would regard the world's stock of a metal as a 'revolving stock' - to be used over and over and only replenished by 'new' metal to the extent needed to make good losses due to fair wear and tear and to provide for new uses.

'Scrap' is already a substantial part of the immediate raw material of these industries. But scrap is produced where metal goods are made and used; so that this part of the raw material comes back from the markets. Thus it tends to increase the pull of the market on the location of the industry, and so to strengthen the factors which keep it in the regions of developed industry.

The increase in the number of different materials needed by an industry necessarily lessens the relative importance of each one of them. So the complex industry, by spreading its dependence over a wider range of natural resources, becomes less dependent on the location of any one of them; and as the factors which influence its location thus become more numerous, the possibilities of effective intervention to control that location become greater.

\section{MINERALS, OLD AND NEW, FROM THE SEA*}

\section{By DR. E. F. ARMSTRONG, F.R.S.}

$\mathrm{H}$ AD I been writing a book on the subject I should have first described the crust of the earth, some 20 miles in thickness, and then gone on to point out how, by the processes of destruction and denudation, this is continually being washed first into the rivers and finally into the sea, much of it going into solution. As the poet tells us, "even the weariest river winds somewhere safe to sea". The quantity of any one constituent of the crust in a thousand parts of sea-water is infinitely small and indeed many are only detectable by the most refined methods of the chemist, but there is so much ocean in the world that in the aggregate it contains many tens of thousands of tons of even the very rarest constituent.

In the past, but for one constituent-common salt - sea-water has never been regarded as a source of raw materials for industry. To-day three other essential substances-potash, bromine and magnesium salts-are being extracted in considerable quantity from the sea by methods which are both novel and

* Paper read at the Conference on Mineral Resources and the Atlantic Charter, arranged by the Division for the Social and International Relations of Science of the British Association, on July 25. interesting. Such methods open up an avenue to the winning of other even scarcer but coveted minerals.

Common salt is an essential for both man and beast, and those countries which lack it go to any end to obtain it. In New Guinea, for example, it was used by traders not so long ago as the best currency for the purchase of native goods. In Britain and in Europe there are large deposits of pure salt resulting from the drying up of inland seas in past geological ages. The Dead Sea in Palestine is an example of such a sea in process of evaporation. At Stassfurt in Germany the sea dried up entirely, so that both the salt and the mixture of potassium and magnesium chlorides, sulphates and bromides remain in the earth, though, strange to say, there is no iodine.

The composition of the ocean varies considerably in different places and at different depths. The salinity expressed as total salts per 1,000 parts of sea-water varies from a minimum in the southern part of the Indian Ocean, 33.01 parts, to a maximum from the middle of the North Atlantic, $37 \cdot 37$ parts.

In hot countries the sea is led into basins and allowed to evaporate in the heat of the sun until first the calcium sulphate and then the salt crystal. lizes : the salt is impure but suffices. The bittern or residue is of no commercial value though it has been further treated to obtain potash in an Italian colony.

The export of salt from England has for long been a significant part of our overseas trade. Together with the chemical products made from it, for salt is one of the foundations of chemical industry, it has helped to make Liverpool one of the world's greatest ports.

The exploitation of any particular source of a mineral is determined by economic considerations. Bromine affords a good example: so long as the demand for it was relatively small, the Stassfurt monopoly maintained it at a high price. When it was required in very large amounts to make 'ethyl', other cheaper sources had to be found. One of these is the Dead Sea, which is a half-evaporated inland sea situated in a climate where there is more evapora. tion than precipitation. As the concentration of salts at the bottom of the lake is greater than that at the surface, the solution is pumped from depth, concentrated and processed to obtain potash salts and bromine, thus affording a British Empire source of these minerals. There are similar inland lakes in the United States. The Americans went to the sea itself for their bromine, having devised a simple method of extracting the traces of bromine from very large quantities of water. At first they fitted up a ship as a floating chemical factory so as to ensure new water all the time. Later the factory was put on land, the effluent water being run to the other side of an isthmus so that it never mixes with the untreated incoming water. It requires 4,000 gallons of sea-water to yield a pound of bromine, so that a factory making only 50 million pounds, say 25 thousand tons, a year has to pump a great deal of the sea through its apparatus. The seawater is made of a particular acidity, the right amount of chlorine gas added, and the free bromine so liberated is blown out by a stream of air counter current to the water which is falling down high towers with wooden packing. It is absorbed in soda solution, forming bromides and bromates. The process is continuous and automatic and under instrumental control : it is one of the triumphs of 